\title{
Antisense correction of SMN2 splicing in the CNS rescues necrosis in a type III SMA mouse model
}

\author{
Yimin Hua, ${ }^{1}$ Kentaro Sahashi, ${ }^{1}$ Gene Hung, ${ }^{2}$ Frank Rigo,${ }^{2}$ Marco A. Passini, ${ }^{3}$ C. Frank Bennett ${ }^{2}$ \\ and Adrian R. Krainer ${ }^{1,4}$ \\ ${ }^{1}$ Cold Spring Harbor Laboratory, Cold Spring Harbor, New York 11724, USA; ${ }^{2}$ Isis Pharmaceuticals, Carlsbad, California 92008, \\ USA; ${ }^{3}$ Genzyme Corporation, Framingham, Massachusetts 01701, USA
}

\begin{abstract}
Increasing survival of motor neuron 2, centromeric (SMN2) exon 7 inclusion to express more full-length SMN protein in motor neurons is a promising approach to treat spinal muscular atrophy (SMA), a genetic neurodegenerative disease. Previously, we identified a potent $2^{\prime}-O$-(2-methoxyethyl) (MOE) phosphorothioate-modified antisense oligonucleotide (ASO) that blocks an SMN2 intronic splicing silencer element and efficiently promotes exon 7 inclusion in transgenic mouse peripheral tissues after systemic administration. Here we address its efficacy in the spinal cord-a prerequisite for disease treatment-and its ability to rescue a mild SMA mouse model that develops tail and ear necrosis, resembling the distal tissue necrosis reported in some SMA infants. Using a microosmotic pump, we directly infused the ASO into a lateral cerebral ventricle in adult mice expressing a human SMN2 transgene; the ASO gave a robust and long-lasting increase in SMN2 exon 7 inclusion measured at both the mRNA and protein levels in spinal cord motor neurons. A single embryonic or neonatal intracerebroventricular ASO injection strikingly rescued the tail and ear necrosis in SMA mice. We conclude that this MOE ASO is a promising drug candidate for SMA therapy, and, more generally, that ASOs can be used to efficiently redirect alternative splicing of target genes in the CNS.
\end{abstract}

[Keywords: Spinal muscular atrophy; SMN2; antisense oligonucleotide; splicing correction; spinal cord; mouse models] Supplemental material is available at http://www.genesdev.org.

Received April 23, 2010; revised version accepted June 8, 2010.

Spinal muscular atrophy (SMA) is an autosomal recessive neuromuscular disease caused by progressive loss of $\alpha$-motor neurons in the anterior horn of the spinal cord. There are three types of childhood-onset SMA, based on the severity and the time of onset: Type I is most severe, and type III is a mild form (Munsat and Davies 1992; Crawford 2003; Russman 2007; Wang et al. 2007). Type IV is adult-onset SMA. There are currently no effective therapies for SMA.

Reduced expression of functional survival motor neuron (SMN) protein is responsible for SMA (Lefebvre et al. 1995, 1997; Coovert et al. 1997). SMN is expressed from two linked paralogous genes: Survival of motor neuron 1 , telomeric (SMN1) and Survival of motor neuron 2, centromeric (SMN2). SMN is localized mainly in the cytoplasm and nuclear gems in all cells (Liu and Dreyfuss 1996), as well as in motor neuron axons (Zhang et al. 2006), and its best-understood function is mediating the

${ }^{4}$ Corresponding author.

E-MAIL krainer@cshl.edu; FAX (516) 367-8453.

Article published online ahead of print. Article and publication date are online at http://www.genesdev.org/cgi/doi/10.1101/gad.1941310. assembly of spliceosomal small nuclear ribonucleoprotein particles (snRNPs) (Meister et al. 2001; Pellizzoni et al. 2002; Kolb et al. 2007). In SMA patients, SMN1 is homozygously deleted or mutated; however, the presence of at least one copy of SMN2 allows viability, although it cannot fully compensate for SMN1 loss of function because of an altered pattern of splicing in SMN2.

Mice have only one SMN1 ortholog, Smn. Human SMN2 can rescue the embryonic lethality of $S \mathrm{mn}^{-/-}$mice, and these transgenic mice display SMA-like phenotypes to varying degrees, depending on the transgene's copy number and expression levels, and the nature of the deletion alleles (Schrank et al. 1997; Hsieh-Li et al. 2000; Monani et al. 2000). The defects in snRNP assembly in SMA mouse tissues correlate with phenotypic severity (Gabanella et al. 2007). The phenotypes can include muscle weakness, premature death, reduced body size and weight, and/or tail and ear necrosis. Mice with a severe SMA phenotype resembling human type I SMA survive $<1-2 \mathrm{wk}$, and typically have two copies of the SMN2 transgene. So-called $\Delta 7$ mice have also been generated that express high levels of human cDNA lacking exon 7, in addition to carrying two copies of the SMN2 transgene in a homozygous-null mouse Smn 
background (Le et al. 2005). Mice that survive and breed normally, but develop tail and ear necrosis, are classified as type III (Hsieh-Li et al. 2000); they have four copies of the SMN2 transgene, and a homozygous replacement of exon 7 and some of flanking intron sequences of the mouse Smn gene with an HPRT cassette (Hsieh-Li et al. 2000; Gogliotti et al. 2010). Tail and ear necrosis have also been observed in type I SMA and $\Delta 7$ mice after various treatments that extended their survival (Narver et al. 2008; Meyer et al. 2009; Foust et al. 2010; Passini et al. 2010; Riessland et al. 2010). Consistent with these observations in SMA mouse models, distal necrosis associated with anomalous vascular perfusion was reported recently as a clinical feature in two infants with type I SMA (Araujo Ade et al. 2009). These and other mouse SMA models are invaluable tools for validating and improving the efficacy of various lead compounds under development as SMA drugs.

Various approaches have been undertaken to treat SMA (Lunn and Wang 2008). Recently, it was shown that AAV (adeno-associated virus)-mediated SMN overexpression rescued the severe phenotype of $\triangle 7$ SMA mice (Foust et al. 2010; Passini et al. 2010). SMN2 targeted drug screens to correct $S M N 2$ splicing and enhance $S M N 2$ transcription, translation, or stability have been an important theme in therapeutics development for SMA. A number of compounds, such as histone deacetylase (HDAC) inhibitors, have been identified that can significantly increase cellular SMN protein levels, and some of them are currently in clinical trials (Lunn and Wang 2008). Several antisense approaches have been undertaken to correct SMN2 splicing, such as blocking exonic splicing silencers (EESs)/ intronic splicing silencers (ISSs) or the intron 7-exon 8 junction, and using bifunctional or chimeric antisense oligonucleotides (ASOs), or trans-splicing RNAs (Lim and Hertel 2001; Miyajima et al. 2002; Cartegni and Krainer 2003; Skordis et al. 2003; Madocsai et al. 2005; Singh et al. 2006; Coady et al. 2007; Geib and Hertel 2009); some of these strategies have shown beneficial effects in SMA model mice (Baughan et al. 2009; Meyer et al. 2009; Coady and Lorson 2010).

Singh et al. (2006) discovered an intron 7 ISS in the human SMN1/2 genes, termed ISS-N1; ASOs that block ISS-N1 strongly enhance SMN2 exon 7 inclusion in cultured patient fibroblasts. Using an ASO-tiling method, we systematically analyzed the elements in and flanking $S M N 2$ exon 7 that modulate exon 7 inclusion in cell-free splicing and in cultured cells (Hua et al. 2007, 2008). By comparing hundreds of ASOs that target various splicing silencers in exon 7 and both flanking introns (Hua et al. 2008; data not shown), we identified an optimal $18 \mathrm{mer}$ 2'-O-(2-methoxyethyl) (MOE) ASO (\#10-27) that targets ISS-N1 in intron 7. The lead ASO also promotes efficient $S M N 2$ exon 7 inclusion in the liver and kidneys of transgenic mice after systemic administration, but not in the spinal cord (Hua et al. 2008), owing to a lack of distribution across an intact blood-brain barrier (BBB) (Geary et al. 2003).

In a recent study, Williams et al. (2009) directly delivered a 2'-O-methyl (2'-OMe) phosphorothioate $(\mathrm{P}=\mathrm{S})$ ASO targeting ISS-N1 into the CNS by repeated neonatal intracerebroventricular (ICV) injections in the $\Delta 7$ mouse model. They reported a small increase in SMN protein and full-length (FL) SMN2 mRNA in the spinal cord, as well as improvements in weight gain and the righting response (Williams et al. 2009). However, only one dosing regimen was tested, an effect on survival was not assessed, and several ASO-treated and control mice died prematurely (Williams et al. 2009). In addition, the expression of prespliced mRNA from the human $\triangle 7 \mathrm{cDNA}$ in this strain makes it more challenging to accurately measure changes in the relative levels of exon 7 inclusion and skipping in mRNA expressed from the SMN2 transgene.

In the present study, we thoroughly investigated and optimized the in vivo efficacy of ISS-N1-directed ASOs in the CNS, including validation of the mechanism of action, pharmacokinetic (PK) and pharmacodynamic (PD) profiles, and effects of oligonucleotide size and base modifications, as well as method of delivery and dosing regimen. To avoid survival issues in mice with very short life spans, and to facilitate accurate measurements of mRNA splicing as well as of the long-term efficacy and metabolism of the ASOs, we initially characterized our lead MOE ASO, delivered by ICV infusion, in the CNS of adult mice of a type III SMA model strain (Hsieh-Li et al. 2000). The ASO promoted very efficient expression of FL $S M N 2$ mRNA and protein in the spinal cord, including motor neurons. Remarkably, the effect persisted for several months after ICV infusion for only $7 \mathrm{~d}$. The favorable PK/ PD profile of the ASO allowed us to test its therapeutic efficacy by using a single embryonic or neonate ICV injection in the mild SMA mouse model. We show that the ASO can successfully rescue the distal tissue necrosis phenotype in the type III mouse model, demonstrating that this ASO is a promising drug candidate for SMA therapy.

\section{Results}

\section{ASO administration into adult mouse spinal cord}

To analyze the effects of ASO 10-27 in mouse CNS, we used ICV infusion to deliver the ASO into the cerebrospinal fluid (CSF). Controlled delivery was achieved by means of a micro-osmotic pump implanted subcutaneously and connected through a catheter to a cannula surgically implanted into the right lateral ventricle, a procedure suitable for adult mice. ASO solution was infused into the CSF for $7 \mathrm{~d}$ at $0.5 \mu \mathrm{L} /$ per hour, and tissues were analyzed on the eighth day. We first performed a dose response study with type III SMA heterozygous mice $\left(\mathrm{Smn}^{+/-} ; \mathrm{SMN2}^{+/+}\right)$with four copies of an SMN2 transgene. Radioactive RT-PCR of thoracic spinal cord RNA with human-specific primers demonstrated a dosedependent increase in exon 7 inclusion (Fig. 1A,B). After ASO infusion at $10 \mu \mathrm{g}$ per day, exon 7 inclusion in the SMN2 transgene mRNA increased to $>30 \%$, compared with $\sim 10 \%$ in saline-treated mice, and $\sim 90 \%$ inclusion was achieved at a dose of $50 \mu \mathrm{g}$ per day. The effect plateaued at $100 \mu \mathrm{g}$ per day, which gave $\sim 96 \%$ exon 7 inclusion. RNA samples were also analyzed for SMN2 splicing by real-time RT-PCR with separate primer pairs for the inclusion and skipping isoforms, with consistent results (Fig. 1C). 


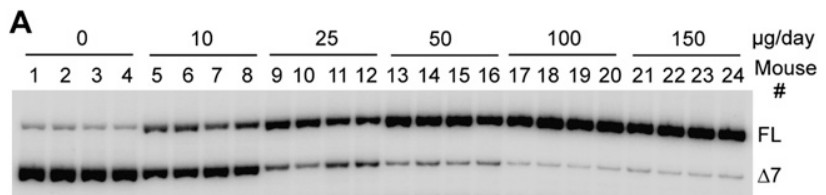

$1010993133253267756263878489859697979795979796 \%$ incl

B

D

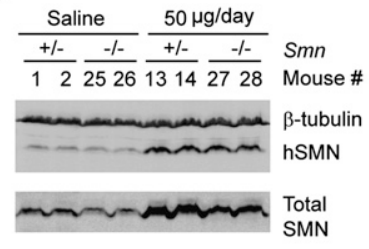

C

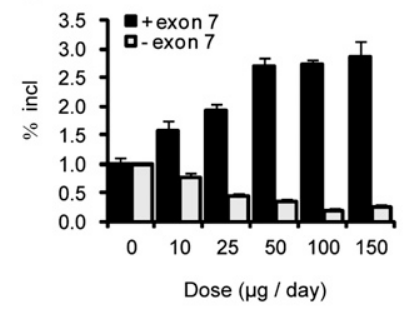

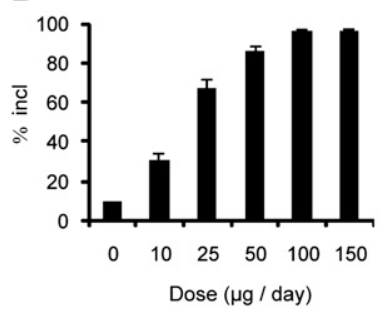

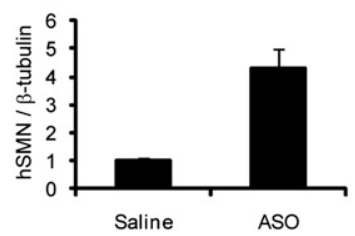

Figure 1. Dose response study of ASO 10-27 in the spinal cord after ICV infusion in adult mice. ASO 10-27 at the indicated daily doses was infused for $7 \mathrm{~d}$ into the right cerebral lateral ventricle of type III SMA heterozygous mice. On day 8, mice were euthanized. $(A)$ Thoracic spinal cord RNA samples were analyzed by radioactive RT-PCR. FL and $\Delta 7$ represent fulllength and exon 7-skipped SMN2 transcripts, respectively; "\% incl" is the percentage of the FL spliced mRNA in total SMN2 transcripts. Four representative samples are shown for each dose. $(B)$ Quantitation of the data in $A$ plus unpublished data $(n=$ 5) (Y Hua and AR Krainer, unpubl.). Error bars represent standard deviations $(\mathrm{SD})$. (C) Quantitation by real-time RT-PCR. Both the FL mRNA (+exon 7) and exon 7-skipped mRNA (-exon 7) $(n=5)$ were normalized with GAPDH, and the data were further normalized to the level of the corresponding transcript in the saline-treated controls (dose, $0 \mu \mathrm{g}$ per day). (D) Thoracic spinal cord protein samples obtained from four heterozygotes (the same mice as in $A$ ) and four additional homozygotes, treated with either saline or $50 \mu \mathrm{g}$ per day of ASO, were analyzed by Western blotting with antibodies SMN-KH (hSMN) or SMN-BD (total $\mathrm{SMN}) ; \beta$-tubulin was used as a loading control. Histograms on the right show the protein quantitation.

To establish that the increase in SMN2 FL mRNA in the spinal cord results in increased hSMN protein, we performed Western blots with a new human SMN-specific monoclonal antibody (mAb) (SMN-KH) (Supplemental Fig. $\mathrm{S} 1$ ), and a commercial $\mathrm{mAb}$ (SMN-BD) that recognizes both human and mouse SMN. ASO treatment resulted in a clear dose-dependent increase in hSMN protein levels, paralleling that of FL SMN2 mRNA levels (Supplemental Fig. S2). A 4.3-fold mean increase in hSMN protein levels was observed after treatment with $50 \mu \mathrm{g}$ of ASO per day (Fig. 1D). Thoracic spinal cord samples from several type III SMA homozygous mice $\left(\mathrm{Smn}^{-/-}\right.$; $\left.S M N 2^{+/+}\right)$treated with $\geq 50 \mu \mathrm{g}$ of ASO per day for $7 \mathrm{~d}$ also showed a robust hSMN protein level increase. In the presence of the ASO, the transgene expressed higher levels of protein than the endogenous mouse Smn gene, and the hSMN protein levels in treated homozygotes were much higher than the total SMN levels in untreated heterozygotes (Fig. 1D; Supplemental Fig. S2).

In addition, mRNA and protein samples from the brain cortex of the same mice also exhibited strong increases in both FL SMN2 transcripts and hSMN protein levels (Supplemental Fig. S3). These data clearly demonstrate that ASO 10-27 delivered into the CNS by direct administration into the CSF rescues splicing of the SMN2 transgene, resulting in robust FL SMN protein increase.

\section{Spinal cord immunostaining of ASO and hSMN protein after ICV infusion}

We next asked how these ASOs distribute in cells in the spinal cord, and whether the increase in SMN protein can be detected in individual motor neurons by immunohistochemistry. To this end, thoracic spinal cord tissues were fixed and sectioned. The sections were stained with either a polyclonal antibody (pAb) that specifically recognizes phosphorothioate-modified ASOs (Butler et al. 1997), or with SMN-KH mAb (Fig. 2A). ASO was detected in both the cytoplasm and the nucleus of individual neurons in a dose-dependent manner, with the majority of the ASO accumulating in the nucleus. Moreover, as the ASO dose increased, hSMN protein staining likewise became stronger in both compartments. ASO infusion at $\geq 50 \mu \mathrm{g}$ per day for $7 \mathrm{~d}$ resulted in many more gems, compared with the controls. We further performed coimmunofluorescence with thoracic spinal cord sections using $\mathrm{SMN}-\mathrm{KH} \mathrm{mAb}$ and a $\mathrm{pAb}$ recognizing choline acetyltransferase (ChAT), a motor neuron marker. We observed a pronounced increase in both the SMN signal and the number of gems in motor neurons after the 7-d ICV infusion at 50 $\mu \mathrm{g}$ per day (Fig. 2B; Supplemental Fig. S4). Gem number is a positive indicator of SMN protein levels (Coovert et al. 1997), and thus these data confirm and extend the above RT-PCR and Western blotting analyses.

\section{ASO effects throughout the spinal cord and persistence of the effect}

When ASOs are infused into the lateral ventricles and travel down to distal neuronal tissues following the CSF flow, neurons in the upper spinal regions may take up the ASOs more efficiently than the lower regions. To address this issue, we compared cervical, thoracic, and lumbar spinal cord RNA samples from mice treated with either 25 or $50 \mu \mathrm{g}$ of ASO 10-27 per day for $7 \mathrm{~d}$, or with a mismatch MOE ASO as a control. At the lower dose, we observed significantly lower levels of exon 7 inclusion in the lumbar region than in the other two regions (Fig. $3 \mathrm{~A}, \mathrm{C})$. However, at $50 \mu \mathrm{g}$ per day, we did not observe significant differences among different regions of the spinal cord, indicating that this dose is sufficient for the distal spinal cord to accumulate a comparable amount of ASOs as the proximal spinal cord (Fig. 3A,C). Furthermore, this dose of ASOs probably results in maximal occupancy of pre-mRNA-binding sites in all spinal cord segments. 

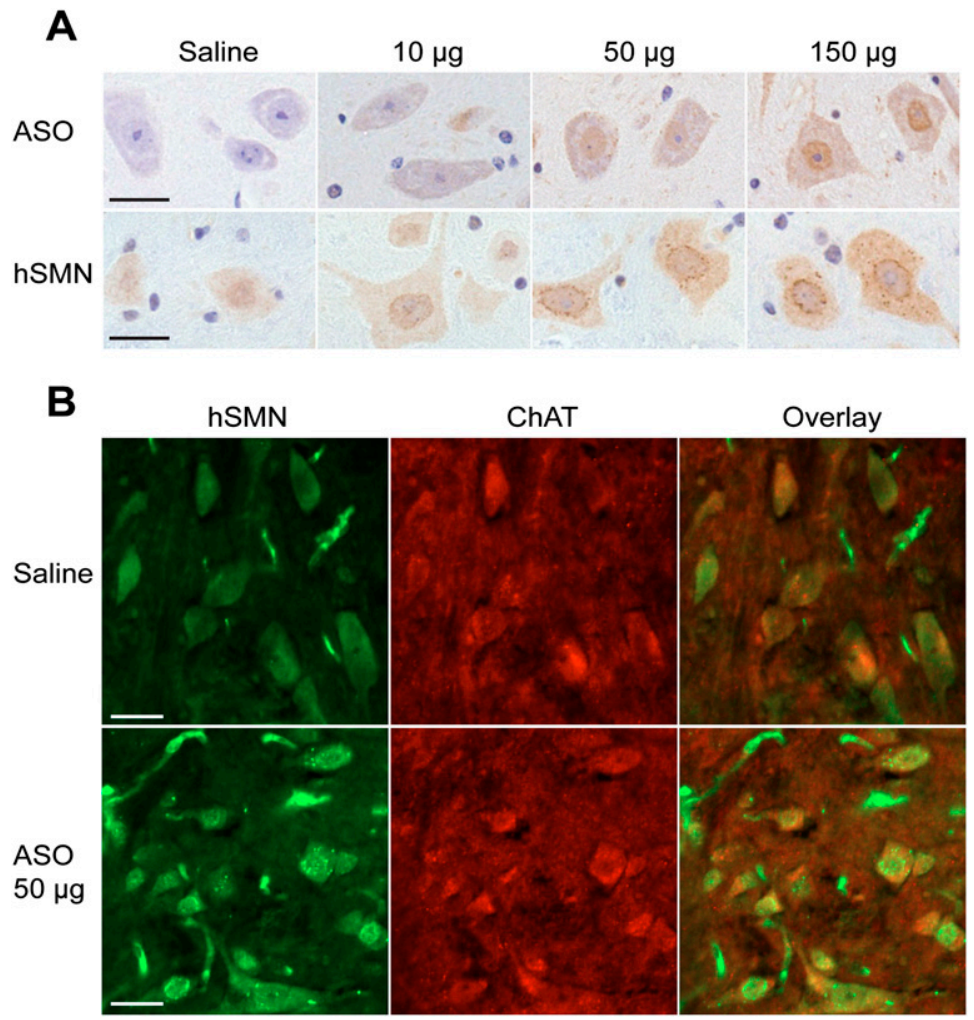

Figure 2. Detection of ASO 10-27 and hSMN protein in spinal cord by immunostaining after ICV infusion. (A) Thoracic spinal cord samples isolated $1 \mathrm{~d}$ after 7 d ICV infusion of saline or ASO 10-27 at the indicated daily doses were analyzed by immunohistochemistry with a pAb that specifically recognizes the phosphorothioate backbone in ASOs, or with SMN-KH mAb specific for human SMN. Nuclei were counterstained with DAPI. (B) Confocal immunofluorescence images of thoracic spinal cord double-labeled with SMN-KH mouse $\mathrm{mAb}$ and anti-ChAT rabbit $\mathrm{pAb}$, followed by incubation with goat Alexa fluor 488 anti-mouse and Alexa fluor 568 anti-rabbit secondary antibodies. Bars, $25 \mu \mathrm{m}$.
To determine the duration of action and tissue half-life of the ASO, heterozygous type III SMA mice were treated with $50 \mu \mathrm{g}$ of ASO per day for $7 \mathrm{~d}$ by ICV infusion, and the animals were sacrificed at various times after infusion for up to 6 mo (Fig. 3B,D). Saline and mismatch ASO-treated mice were used as controls, and showed a constant level of $\sim 10 \%$ exon 7 inclusion in the spinal cord (Fig. $3 \mathrm{~B}$; data not shown). Remarkably, RT-PCR analysis showed that the ASO still promoted $\sim 90 \%$ SMN2 exon 7 inclusion half a year after completing the 7 -d treatment, suggesting that this ASO is extremely stable in CNS tissues. Importantly, at all of the doses tested, the mice showed no signs of toxicity throughout the time-course experiment. We measured the ASO concentration in spinal cord tissue by capillary gel electrophoresis and observed no reduction in tissue concentration over a 2-mo period (Supplemental Fig. S5). Although the very long half-life of the ASO in mouse spinal cord tissue is striking, it was not unexpected, given that nuclease activity in neuronal tissue is lower than in peripheral tissues (Whitesell et al. 1993), and that the uniform MOE ASO is less susceptible to endonucleases than traditional MOE gapmers.

\section{ICV infusion of MOE ASO does not lead to CNS inflammation}

Because prolonged inflammation is associated with many neurodegenerative diseases (Glass et al. 2010), we tested whether the MOE ASO induces inflammation in the mouse CNS. We compared the MOE ASO with the 2 '-OMe ASO that was used by Williams et al. (2009) and Singh et al. (2006). The mismatch MOE ASO was used as a control. Two days after 7-d ICV infusion of each ASO at different doses in type III SMA mice, we examined the expression of allograft inflammatory factor-1 (Aif1) in both the brain and the lumbar spinal cord using real-time RT-PCR. AIF1 is a marker of monocyte/microglial activation, and plays an important role in the immune response (Yang et al. 2005). We observed no increase of Aif1 mRNA level in the brain after the treatment of the MOE ASO at various concentrations. In the lumbar spinal cord, there was a $20 \%$ increase in Aif1 mRNA expression at only the highest dose of MOE ASO $(100 \mu \mathrm{g}$ per day; $P=$ 0.01) (Fig. 4). After treatment with the mismatch ASO, Aif1 displayed a similar expression pattern, with slight variations, as that in the MOE ASO-treated brain and spinal-cord samples. In contrast, after treatment with the 2 '-OMe ASO at $10 \mu \mathrm{g}$ per day, we observed a 1.8 -fold increase in Aif1 mRNA expression. At the highest dose tested, the 2'-OMe ASO resulted in a 3.3-fold and 1.8-fold increase in Aif1 mRNA expression in the lumbar spinal cord and the brain, respectively.

We also examined the effect of the three ASOs on splicing of SMN2. RNA samples from the brain and the lumbar spinal cord were analyzed by real-time RT-PCR, as above. Surprisingly, the 2'-OMe ASO had no stimulatory effect on SMN2 exon 7 inclusion, similar to the mismatch control ASO, whereas the MOE ASO showed the same potent stimulatory effect on SMN2 exon 7 splicing as described above (Supplemental Fig. S6). Based on these data, we conclude that the MOE ASO is a safer and much more effective drug candidate than the 2 '-OMe ASO. 
A

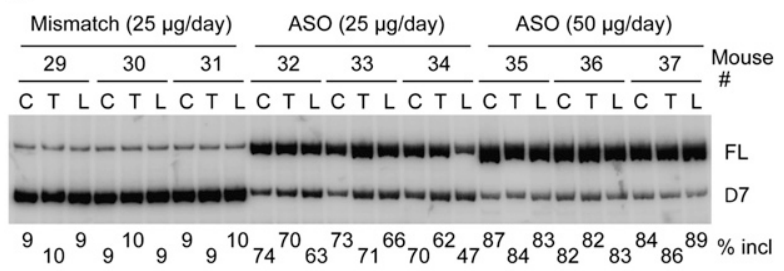

B

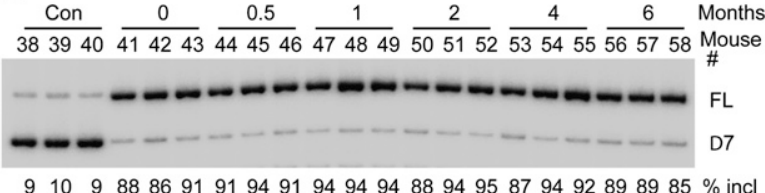

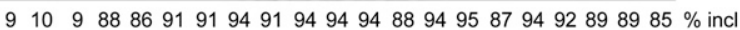

C
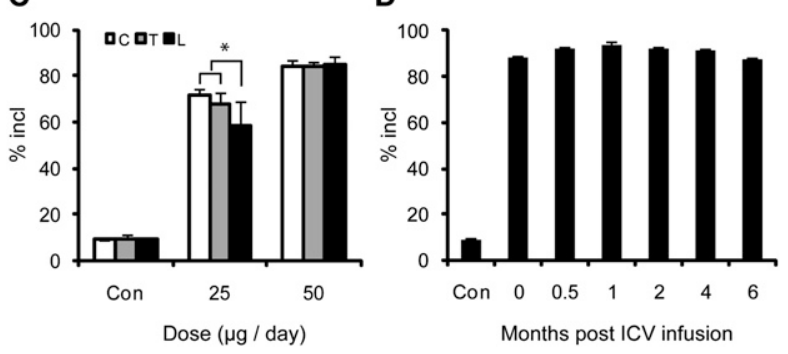

Figure 3. RT-PCR analysis of SMN2 splicing in different regions of the spinal cord, and duration of action of ICV-infused ASO 10-27. (A) Total RNA samples isolated from the cervical $(C)$, thoracic $(\mathrm{T})$, or lumbar $(\mathrm{L})$ spinal cord of mice treated by $7-\mathrm{d}$ ICV infusion with the indicated daily doses of ASO 10-27 or a sixmismatch control ASO were analyzed by radioactive RT-PCR as in Figure 1. Representative triplicate samples out of four mice for each dose are shown. (B) After a 7-d ICV infusion of type III SMA model heterozygous mice at $50 \mu \mathrm{g}$ per day, total RNA samples were prepared from thoracic spinal cord isolated at the indicated time points ( 0 indicates $1 \mathrm{~d}$ after ICV infusion) and analyzed by radioactive RT-PCR. (Con) Saline-treated controls. Representative triplicate samples from four to five mice for each time point are shown. $(C)$ Quantitation of SMN2 splicing in different regions of the spinal cord. An asterisk $\left(^{*}\right)$ indicates a significantly lower percentage of exon 7 inclusion in the lumbar than in the cervical region $(P=0.045, n=4$, two-tailed paired Student's $t$-test $)$ and thoracic regions $(P=0.031, n=4)$. $(D)$ Quantitation of the duration-of-action data $(n=4-5)$. For all of the time points, the difference from the control was highly significant $(P \leq 9.3 \times$ $10^{-9}$, two-tailed Student's $t$-test). Error bars, SD.

\section{Embryonic ICV administration}

We next sought to determine whether the MOE ASO could rescue the SMA phenotype in mice. Type III SMA mice display no muscle weakness, but have progressive tail necrosis beginning at $\sim 3$ wk postnatally, and ear necrosis at $\sim 4-5 \mathrm{wk}$; they lose the tail completely in 5-6 wk, or are left with a short stub of dead tissue for several days, in addition to gradually losing most of their ears (Hsieh-Li et al. 2000; data not shown). To prevent or delay the onset of necrosis in type III SMA mice, it is necessary to treat them as early as possible. Therefore, instead of the ICV infusion procedure, which is only suitable for adult mice, and in light of the very long half-life of the MOE ASO in the CNS, we used ICV injection in embryos. We transiently exteriorized the uterus of pregnant females at approximately embryonic day 15 (E15), and used a glass capillary to inject the MOE ASO as a single $2-\mu \mathrm{L}$ dose into a brain lateral ventricle of individual embryos.

We performed a dose response study in embryos from crosses between heterozygous mice to measure how much ASO is required to promote SMN2 exon 7 inclusion, using single doses ranging from 0 to $20 \mu \mathrm{g}$ in saline. The ASO effects were assayed at postnatal day 7 (P7). RT-PCR analysis of the lumbar spinal cord samples revealed that $2.5 \mu \mathrm{g}$ and $5 \mu \mathrm{g}$ of the ASO induced $62 \%$ and $77 \%$ exon 7 inclusion, respectively, whereas salinetreated controls showed only $11 \%$ inclusion (Fig. 5A). Doses of 10 and $20 \mu \mathrm{g}$ both resulted in an average of $88 \%$ exon 7 inclusion (Fig. 5A), indicating that the maximal

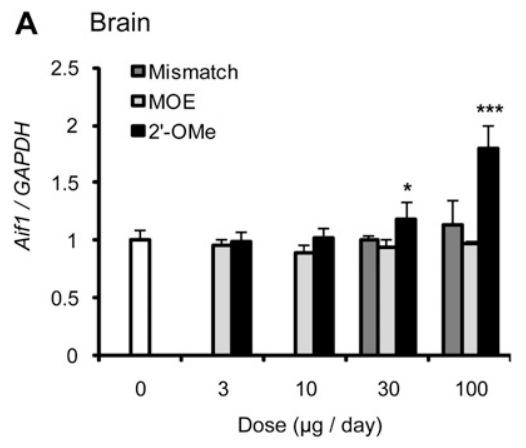

B Spinal cord

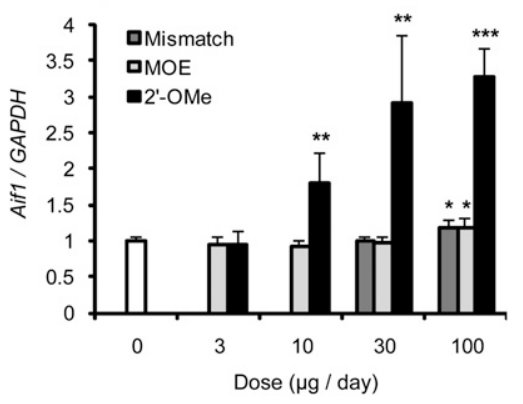

Figure 4. 2'-OMe but not MOE ASO induces an increase in Aif1 expression, a marker of microglial activation. The MOE ASO (MOE), a six-mismatch ASO (Mismatch), and the 2 '-OMe ASO (2'-OMe) (for sequences, see the Materials and Methods) were delivered into the CNS of heterozygous type III SMA mice by ICV infusion for $7 \mathrm{~d}$ at the indicated doses $(n=5$ for all doses, except for the 2 '-OMe treatment at $100 \mu \mathrm{g}$ per day, for which two mice died prematurely). On day 9 , mice were euthanized, and the whole brain $(A)$ and lumbar spinal cord $(B)$ were collected for total RNA extraction. Aif1 mRNA levels were analyzed by real-time RT-PCR with specific primers and normalized to GAPDH mRNA. The data were further normalized to the saline controls (dose, $0 \mu \mathrm{g}$ per day, white bars). MOE ASO gave no increase of Aif1 expression in the brain, and a 1.2-fold increase at only the highest dose (100 $\mu$ g per day) in the lumbar spinal cord $(P=0.01)$. 2 '-OMe ASO caused a large increase in Aif1 mRNA levels at doses $\geq 10 \mu \mathrm{g}$ per day in the spinal cord, and at doses of $100 \mu \mathrm{g}$ per day in the brain. Error bars represent standard deviations. $\left(^{\star}\right) P<0.05 ;\left(^{\star \star}\right)$ $P<0.01 ;\left(^{\star \star \star}\right) P<0.001$, compared with the saline controls. 
A

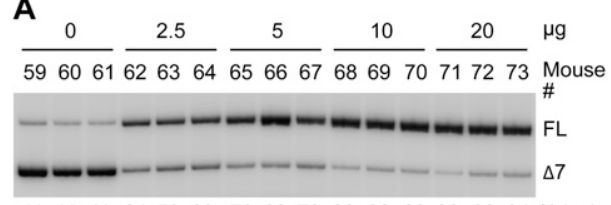

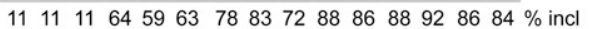

B

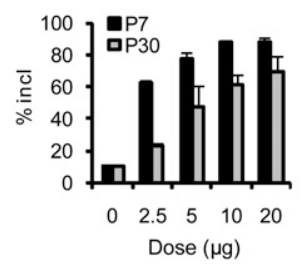

C

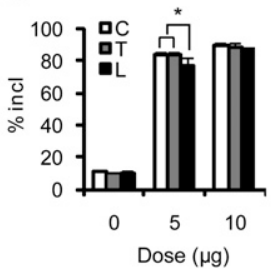

Figure 5. Dose response study of ASO 10-27 in the lumbar spinal cord after a single embryonic ICV injection. Using a glass micropipette, $2 \mu \mathrm{L}$ of ASO 10-27 was injected into a cerebral lateral ventricle of individual embryos at approximately E15 $\left(\mathrm{Smn}^{+/-}\right.$or $\mathrm{Smn}^{-/-}$; $\left.S M N 2^{+/+}\right)$at the indicated doses. (A) The effect of ASO 10-27 on SMN2 splicing was assayed at P7. Total RNA isolated from the lumbar spinal cord was analyzed by radioactive RT-PCR as in Figure 1. Three representative samples from four to five treated mice are shown. $(B)$ Quantitation of the dose response radioactive RT-PCR data from lumbar spinal cords obtained at P7 or P30 $(n=4-5)$. For all of the doses, the difference between P7 and P30 was significant $(P \leq 0.02$, two-tailed Student's $t$-test). (C) Quantitation of the effects of ASO 10-27 in different spinal cord regions in $\mathrm{P} 7$ neonates; two doses (5 and $10 \mu \mathrm{g}$ ) were chosen for comparison. An asterisk $\left({ }^{*}\right)$ indicates a significantly lower percentage of exon 7 inclusion in the lumbar spinal cord than in the cervical $(P=0.017, n=4$, two-tailed paired Student's $t$-test $)$ and thoracic $(P=0.016, n=4)$ regions.

effect of the ASO was achieved at these doses when measured in $\mathrm{P} 7$ neonates. The ASO effects after a single embryonic injection were also assayed at P30; we observed lower but still highly significant levels of exon 7 inclusion, compared with samples analyzed at P7 (Fig. 5B; Supplemental Fig. S7A). This is an expected result for a single embryonic injection because, with the increase in body size and cell proliferation, the effective concentration of ASO will be reduced. We also compared RNA samples from different spinal cord regions of mice injected with $5 \mu \mathrm{g}$ of ASO (below saturation at P7) and $10 \mu \mathrm{g}$ of ASO (saturated at P7). At the lower dose, there was slightly but significantly less exon 7 inclusion in the lumbar spinal cord than in the other regions (Fig. 5C; Supplemental Fig. S7B). We also tested $30 \mu \mathrm{g}$ of ASO for embryonic ICV injection; however, we observed a significant increase in fetal mortality at this dose.

\section{Rescue of tail and ear necrosis in type III SMA mice}

Based on the above dose response study with embryonic ICV injection, we chose doses of 10 and $20 \mu \mathrm{g}$ for therapeutic trials in mice. We set up crosses between $\mathrm{Smn}^{-1-}$; $S M N 2^{+/+}$homozygotes, such that all of the offspring were phenotypically SMA type III. ASO solution $(2 \mu \mathrm{L})$ was again injected ICV into individual embryos at E15, and, after birth, the tail length of each treated pup was measured weekly until 12 wk of age. Remarkably, the treatment rescued both the tail and ear necrosis (Fig. 6A,C). Mice treated with $20 \mu \mathrm{g}$ of ASO showed no sign of necrosis and had intact tails at $2 \mathrm{mo}$, whereas saline-treated, mismatch ASO-treated (data not shown), or untreated (data not

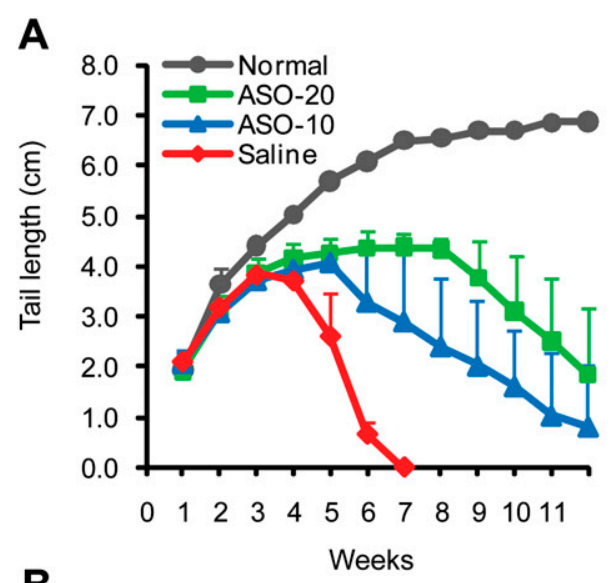

B
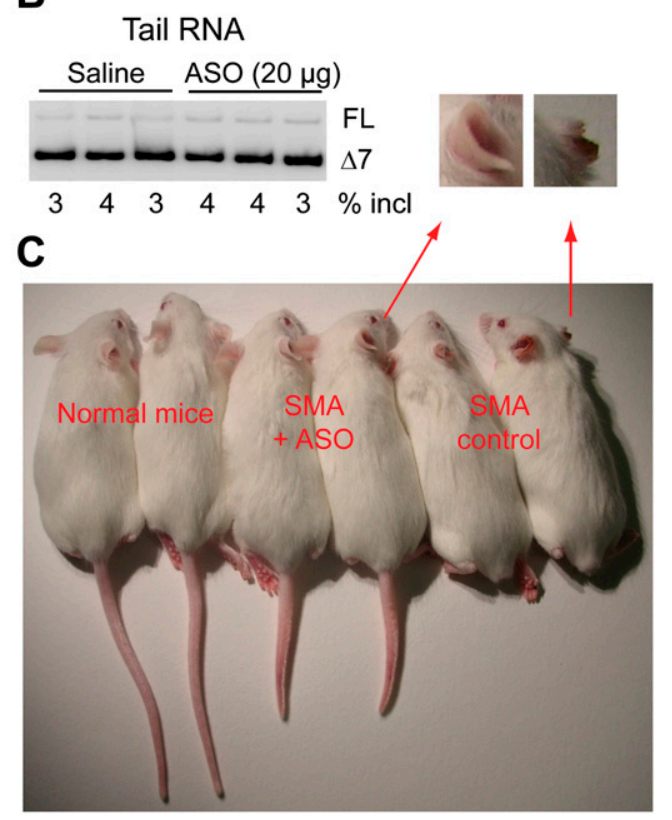

Figure 6. Phenotypic rescue of type III SMA mice $\left(\mathrm{Smn}^{-1-}\right.$; $S M N 2^{+/+}$) after a single embryonic ICV injection of ASO 10-27. (A) Tail lengths were measured from P7 to 12 wk old, at weekly intervals. E15 embryos were injected with saline vehicle $(n=10)$ or $10 \mu \mathrm{g}(n=17)$ (ASO-10) or $20 \mu \mathrm{g}(n=11)$ (ASO-20) of ASO 1027 in a volume of $2 \mu \mathrm{L}$. Normal mice $\left(\mathrm{Smn}^{+/+}\right.$or $\left.\mathrm{Smn}^{+/-}\right)$were used as positive controls $(n=10)$. (B) Radioactive RT-PCR of tail RNA samples obtained from mice treated with saline or $20 \mu \mathrm{g}$ of ASO $10-27$ at approximately E15. $(C)$ Representative 2-mo-old mice to show ASO rescue of tail and ear necrosis. The two mice on the left have normal tails and ears (the one at the far left is $\mathrm{Smn}^{+/-}$; $\mathrm{SMN2}^{+/+}$, and the other one is $\mathrm{Smn}^{+/+}$; $\left.\mathrm{SMN2}^{+/+}\right)$, the two mice in the middle are type III SMA mice $\left(\mathrm{Smn}^{-/-}\right.$; $\mathrm{SMN2}^{+1}$ $\left.{ }^{+}\right)$that were treated as embryos with $20 \mu \mathrm{g}$ of ASO 10-27, and the two SMA mice $\left(\mathrm{Smn}^{-/-}\right.$; $\left.S M N 2^{+/+}\right)$on the right received no treatment. The enlargements show the right ears of one treated and one untreated mouse. 
shown) mice completely lost their tails by $5-6$ wk postnatally. Some mice treated with $20 \mu \mathrm{g}$ of ASO eventually showed tail necrosis starting at $\sim 9-10$ wk of age, and the onset of ear necrosis was generally delayed from 1 mo to $>3$ mo postnatally. Mice treated with the lower dose (10 $\mu \mathrm{g}$ of ASO) also showed a significant delay in the onset of tail and ear necrosis, but had less phenotypic improvement compared with mice treated with $20 \mu \mathrm{g}$ of ASO (Fig. 6A).

To address the possibility that the tail rescue is the result of ASO leakage from the CSF into tail tissue, as opposed to rescue of neurons that innervate tail muscles, we performed RT-PCR analysis with tail RNA samples isolated from P14 mice $\left(\mathrm{Smn}^{-/-} ; \mathrm{SMN2}^{+/+}\right)$that had received an embryonic ICV injection of $20 \mu \mathrm{g}$ of ASO or saline vehicle. We initially chose P14 so that we could compare the tail samples of ASO-treated and control mice several days before the onset of necrosis. We observed no differences in SMN2 exon 7 inclusion among all of these samples, indicating that any potential ASO leakage from the CNS does not reach a sufficient concentration in tail tissue to affect SMN2 splicing (Fig. 6B). Further examination of tail and other peripheral tissues (liver and kidney) at various ages from P7 to P30 gave similar results (data not shown).

Finally, we performed ICV injection of ASO 10-27 in type III SMA neonates. Each cryoanesthesized P1-P2 pup received a single injection into a lateral ventricle of $20 \mu \mathrm{g}$ of ASO in $2 \mu \mathrm{L}$. The onset of tail necrosis was delayed for $\sim 2 \mathrm{wk}$, and part of the tail still remained after $2 \mathrm{mo}$, whereas the saline and mismatch controls showed the same phenotype as untreated controls (Supplemental Fig. S8; data not shown). However, this phenotypic improvement was less pronounced than that in mice treated by a single embryonic injection. We measured SMN2 exon 7 inclusion with lumbar spinal cord at P7 after a single neonatal ICV injection of 10 or $20 \mu \mathrm{g}$ of ASO at P1, and observed $89 \%$ exon 7 inclusion for both doses (data not shown). Therefore, the reduced phenotypic rescue in neonate-treated compared with embryonic-treated mice is a reflection of the timing rather than the extent of splicing correction.

\section{Discussion}

In this study, we directly infused MOE ASO 10-27directed against an intronic splicing silencer in human $S M N 2$ pre-mRNA - into the right lateral ventricle in the brain of adult transgenic mice. RT-PCR and Western blotting showed efficient SMN2 exon 7 inclusion and a robust increase in FL hSMN protein in the brain and throughout the spinal cord. Spinal cord immunostaining showed that hSMN increased in motor neurons-the cells affected in SMA patients. Furthermore, by using a single embryonic or neonatal ICV injection of ASO, we achieved successful phenotypic rescue in a mouse model of type III SMA. These data demonstrate that this MOE ASO is a promising drug candidate to treat SMA.

Tail and ear necrosis is a typical feature in mouse lines with mild forms of SMA (Hsieh-Li et al. 2000; Tsai et al.
2006; Gavrilina et al. 2008). In addition, various treatments of mice with severe forms of SMA can increase their survival long enough for the onset of tail and ear necrosis to be manifested (Narver et al. 2008; Meyer et al. 2009; Foust et al. 2010; Passini et al. 2010; Riessland et al. 2010); for example, Narver et al. (2008) observed tissue ischemia and progressive necrosis of the tail, the pinnae of the ears, and sometimes the hind limbs and pelvis in $\Delta 7$ mice treated with trichostatin A (TSA), and they characterized this phenotype histologically as vascular necrosis. Interestingly, digital necrosis was reported recently as a clinical feature in two cases of SMA type I children whose survival had likely been significantly extended through ventilation and supportive care (Araujo Ade et al. 2009). These clinical observations defined distal necrosis as a symptom of SMA, and thus it appears to be a relevant phenotype for preclinical drug evaluation. Indeed, orally administered valproic acid, a drug being investigated for the treatment of SMA, reduces the extent of tail and ear necrosis in type III SMA C57BL/6J mice (Tsai et al. 2006, 2008). The finding that ICV injection of our lead ASO efficiently rescued tail and ear necrosis, together with our observation that splicing correction is limited to the CNS, suggests that the distal necrosis in type III SMA mice could be caused by skeletal muscle denervation. One possibility is that the mild SMN deficiency in the type III SMA model leads to defective motor units mainly or exclusively in the tail and ears, and the resulting muscle atrophy in turn leads to local ischemia and vascular necrosis (Narver et al. 2008; Tsai et al. 2008). Supplying the therapeutic ASO to the CNS restored cellular SMN levels, which in turn might prevent the deterioration of motor neurons and consequent muscle atrophy. Another possible scenario is that distal necrosis in SMA patients and mouse models may result from vascular perfusion abnormalities related to autonomic nervous system dysfunction (Arai et al. 2005; Araujo Ade et al. 2009). It remains to be seen whether sympathetic and parasympathetic nervous system functions are affected by limiting SMN protein.

We observed that the tails of treated mice were still shorter than those of mice with $\mathrm{Smn}^{+/+}$or $\mathrm{Smn}^{+/-}$; $S M N 2^{+/+}$genotypes. Our interpretation is that, because SMN is essential for embryonic development, the stage at which high levels of SMN are restored is probably important; hence, high levels of SMN beginning at E15, although clearly beneficial, may not be as effective as normal levels beginning at E1 (McWhorter et al. 2003). In addition, the maximal dose given at E15 may gradually become less effective because of dilution as the embryos and pups grow. Although tail necrosis was clearly delayed, it still took place by 2 mo of age; this might be simply explained by the ASO becoming limiting as the mice grew, considering that $20 \mu \mathrm{g}$ is $<6 \%$ of the total amount of $350 \mu \mathrm{g}$ that was required to maintain a high percentage of SMN2 exon 7 inclusion in the CNS of adult mice. However, ASO uptake by spinal motor neurons may be more efficient with embryonic ICV injection than with adult ICV infusion, because embryos have a more open ventricular space and fewer brain cells than adults, 
and therefore a higher proportion of ASO may circulate to the spinal cord in embryos.

Embryonic ICV injection was more effective than neonatal injection in the extent of rescue of tail and ear necrosis, yet, in both cases, a single ICV injection of $\geq 10$ $\mu \mathrm{g}$ of ASO led to $\sim 90 \%$ SMN2 exon 7 inclusion at P7. This observation suggests that the phenotypic improvement difference between the two different injection methods is not just due to a different extent of splicing correction. Therefore, earlier therapeutic intervention is probably more effective, as reported in a previous study of TSA treatment in the $\Delta 7$ mouse model (Narver et al. 2008).

In a recent study, Williams et al. (2009) used a $20 \mathrm{mer}$ 2 '-OMe ASO targeting ISS-N1 to treat severe $\Delta 7$ SMA mice; they administered five bilateral neonatal ICV injections from P1 to P10, adding up to a total dose of $10 \mu \mathrm{g}$. Williams et al. (2009) reported weight gain and an improved righting response in ASO-treated mice, but they did not evaluate potential effects on survival. We compared the potencies of our 18mer MOE ASO with the overlapping 20mer 2'-OMe ASO used by Williams et al. (2009). When the 2'-OMe ASO was delivered by ICV infusion into the adult mouse CNS, we observed no effect on SMN2 exon 7 inclusion (Supplemental Fig. S6). Furthermore, the 2'-OMe ASO-but not the MOE ASO-had a proinflammatory effect in the brain and the spinal cord, as seen by an increase in AIF1/IBA1, a microglial marker (Fig. 4), indicating that the 2'-OMe ASO may be less well tolerated when administered into the CNS. Therefore, it is reasonable to anticipate a much better therapeutic outcome when the MOE ASO is applied instead with an appropriate regimen in the $\Delta 7$ mouse model.

The sustained effect of the lead MOE ASO in promoting SMN2 exon 7 splicing in the mouse CNS can be explained by the high stability of the ASO in CNS tissues. On the basis of our previous data, particularly the in vitro splicing data (Hua et al. 2008), we believe that the ASO exerts its effect mainly, if not exclusively, via blocking the bipartite hnRNP Al motif in ISS-N1. Indeed, we observed that the ASO competes with hnRNP Al for binding to the ISS-N1 RNA sequence (data not shown). However, we did not rule out other epigenetic mechanisms that might also contribute to the persistent ASO effect in vivo, such as the recently described transcriptional gene silencing-regulated alternative splicing (TGSAS) (Allo et al. 2009). However, TGS-AS is elicited by double-stranded siRNAs, which are assembled into an RNA-induced silencing complex (RISC), whereas we used a single-stranded, chemically modified ASO, which does not load into RISC (Lima et al. 2009). In addition, the intron preceding exon 7 in SMN2 is long, which is not typical of characterized TGS-AS substrates. Another formal possibility is that increasing SMN protein concentration above a certain threshold establishes a regulatory loop that helps maintain high levels of exon 7 splicing.

In terms of SMA therapy, because the drug will be administered by an invasive procedure in neonates and young children, it will be an advantage to have a half-life long enough to allow infrequent dosing. Our preclinical data demonstrated that the lead ASO has met such a criterion. The safety of systemically administered MOE oligonucleotides in humans has been well characterized, and no serious side effects have been observed after systemic administration at therapeutically effective doses (Crooke 2004). The main safety issues are potential offtarget hybridization events and potential chemistry classrelated effects. Sequence analysis revealed that this ASO has no other perfect targets, and a 1-base mismatch to only two additional human genes. Given that this oligonucleotide design does not cause cleavage of the target RNA, the potential for adverse effects due to hybridization to nontargeted RNAs is greatly reduced. Additional preclinical studies will be required to fully characterize the safety profile of this ASO in multiple animal species.

The lead ASO already possesses the critical qualities of a drug to treat SMA. Although the inability of ASOs to cross the BBB limits the utility of systemic administration, well-established implantable catheters and pump technology can overcome this obstacle. Intrathecal pumps have been used clinically to deliver drugs to the spinal cord of patients with debilitating chronic pain or severe spasticity (Belverud et al. 2008), and should be suitable for ASO delivery. In addition, our experiments in embryonic mice demonstrate that a bolus injection is also effective. Intrathecal bolus administration is a well-accepted route for drug delivery for infants and young children. Progress is also being made in developing drug carriers to circumvent the BBB. For example, a nanogel carrier system and a short modified viral peptide have shown promise in delivering oligonucleotides through the BBB (Vinogradov et al. 2004; Kumar et al. 2007). Refinement of such strategies may ultimately allow direct systemic administration of ASO for SMA therapy.

\section{Materials and methods}

Oligonucleotide synthesis

The synthesis and purification of ASO 10-27 (5'-TCACTTTCA TAATGCTGG-3') and a six-mismatch control (5'-TTAGTTTAA TCACGCTCG-3') 2'-O-methoxyethyl-modified oligonucleotides with phosphorothioate backbone and all 5-methyl cytosines, and a 2'-OMe-modified phosphorothioate oligonucleotide (5'-AUUC ACUUUCAUAAUGCUGG-3') (Singh et al. 2006; Williams et al. 2009) were performed as described (Baker et al. 1997; Hua et al. 2008). The oligonucleotides were dissolved in $0.9 \%$ saline.

\section{Animals}

All mouse protocols were in accordance with Cold Spring Harbor Laboratory's Institutional Animal Care and Use Committee guidelines. The initial breeding SMA type III model mice were purchased from Jackson Laboratory, and were originally developed by Hsieh-Li et al. (2000). We used strain FVB.Cg$\mathrm{Tg}\left(\right.$ SMN2)2HungSMN1 ${ }^{\text {tm1Hung }} / \mathrm{J}$, founder line 2, stock number 005058.

\section{Cranial surgery and ICV infusion}

The procedure was based on a protocol used with rats (Smith et al. 2006). In brief, adult mice 3-4 moold, of both sexes, weighing 20-30 g were anesthetized and placed on a digital stereotaxic 
instrument (David Kopf Instruments). A small burr hole at the surgical site $(1.8 \mathrm{~mm}$ lateral to the sagittal suture and $0.3 \mathrm{~mm}$ posterior to the bregma suture) was drilled through the skull above the right lateral ventricle, and was used to position a cannula (with a 2.2-mm stylet). The cannula was connected to an Alzet microosmotic pump (model 1007D, Durect Corporation) with a vinyl catheter. The pump, prefilled with ASO solution (or saline only), was implanted subcutaneously on the back, and continuously infused the ASO solution through the cannula into the lateral ventricle at a rate of $0.5 \mu \mathrm{L}$ per hour.

\section{Embryonic ICV injection}

The procedure was modified from an earlier report (Saito 2006). In brief, pregnant mice with approximately E15 embryos were anesthetized, and a 3-cm-long midline incision in the abdomen was made using scissors. The uterus was pulled out of the abdominal cavity with ring forceps and kept wet with warm saline. A glass micropipette was used to deliver ASO solution to one of the cerebral lateral ventricles of each embryo. Fast Green FCF $(0.01 \%[\mathrm{w} / \mathrm{v}]$; Sigma-Aldrich) was included in the ASO solution, so that the shape of both lateral ventricles could be visualized if the ICV injection was successful. A total of $2 \mu \mathrm{L}$ of ASO solution or saline vehicle was injected into each embryo. After injection, the uterus was placed back into the abdominal cavity, and the abdominal wall and the skin were closed with sutures.

\section{Radioactive $R T-P C R$ and real-time RT-PCR}

Twenty milligrams of tissue was pulverized in liquid $\mathrm{N}_{2}$ with mortar and pestle, and homogenized with $1 \mathrm{~mL}$ of Trizol (Invitrogen). Total RNA was isolated according to the manufacturer's directions. One microgram of total RNA was reversetranscribed with ImProm-II Reverse Transcriptase (Promega). Standard amplification and analysis of SMN2 transcripts was performed as described (Hua et al. 2008). Real-time RT-PCR (Smith et al. 2006) was performed on an Applied Biosystems StepOnePlus instrument with an Express One-Step SuperScript Kit, according to the manufacturer's instructions. Each reaction contained $50 \mathrm{ng}$ of total RNA with $300 \mathrm{nM}$ primer concentration and $100 \mathrm{nM}$ probe concentration. The probes for detection of SMN2 transcripts were double-labeled with 5'-6FAM and 3'-MGBNFQ. Primer/probe set sequences for FL SMN2 transcript were forward primer, $5^{\prime}$-GCTGATGCTTTGGGAAGTAT GTTA-3'; reverse primer, 5'-CACCTTCCTTCTTTTTGATTTT GTC-3'; probe, $5^{\prime}$-TACATGAGTGGCTATCATACT-3' . Primer/ probe set sequences for $\Delta 7 S M N 2$ transcript were forward, $5^{\prime}$-TG GACCACCAATAATTCCCC-3'; reverse, 5' -ATGCCAGCATTT CCATATAATAGCC-3'; probe, 5' -TCCAGATTCTCTTGATGA TG-3'. The primer/probe set sequences for Aif1 were forward, 5'-TGGTCCCCCAGCCAAGA-3'; reverse, 5'-CCCACCGTGT GACATCCA-3'; probe, 5'-AGCTATCTCCGAGCTGCCCTGA TTGG-3'. GAPDH mRNA levels were used as an internal reference for normalization.

\section{Western blotting}

Twenty milligrams of tissue was pulverized in liquid $\mathrm{N}_{2}$ and homogenized in $0.4 \mathrm{~mL}$ (liver, kidney, or brain) or $0.2 \mathrm{~mL}$ (spinal cord) of $1 \times$ protein sample buffer containing $2 \%(\mathrm{w} / \mathrm{v})$ SDS, $10 \%$ (v/v) glycerol, $50 \mathrm{mM}$ Tris-HCl (pH 6.8), and 0.1 M DTT. Protein samples were separated by $12 \%$ SDS-PAGE and electroblotted onto nitrocellulose membranes. The blots were probed with $\mathrm{mAb}$ SMN-KH, mAb anti-SMN SMN-BD purchased from BD Biosciences, or pAb anti- $\beta$-tubulin (GenScript), followed by secondary IRDye $800 \mathrm{CW}$-conjugated goat anti-mouse or antirabbit antibody. Protein signals were detected with an Odyssey instrument (LI-COR Biosciences). For Western blotting in the Supplemental Material, chemiluminescence detection was used (see Supplemental Fig. S1).

\section{Immunostaining}

Spinal cord was fixed with $4 \%(\mathrm{v} / \mathrm{v})$ formaldehyde in phosphatebuffered saline (PBS) overnight. ASO and SMN immunohistochemistry was performed as described (Butler et al. 2000). For SMN and ChAT immunofluorescence, fixed tissue was soaked in $30 \%(\mathrm{w} / \mathrm{v})$ sucrose overnight at $4{ }^{\circ} \mathrm{C}$ and embedded in frozen medium. Ten-micron sections were cut and mounted on Superfrost slides (Fisher Scientific). After blocking with $5 \%(\mathrm{v} / \mathrm{v})$ goat serum and $0.2 \%(\mathrm{v} / \mathrm{v})$ Triton X-100 in PBS, tissue was incubated with SMN-KH and rabbit anti-ChAT pAb (Abcam), followed by goat anti-mouse Alexa fluor 488 and goat anti-rabbit Alexa fluor 568 secondary antibodies (Invitrogen). Confocal immunofluorescence images were acquired with an UltraView Vox confocal imaging system (Perkin Elmer) and a Nikon Ti-E inverted microscope (Nikon Instruments) equipped with a $20 \times$ or $40 \times / 0.75 \mathrm{NA}$ objective lens and an Orca ER CCD camera (Hamamatsu Photonics).

\section{Statistical analyses}

We determined statistical significance by two-tailed Student's $t$-tests.

\section{Acknowledgments}

We dedicate this work to the memory of Dr. Hung Li. We gratefully acknowledge support from the Muscular Dystrophy Association. We thank Chris Lorson and Arthur Burghes for helpful discussions, and Carmelita Bautista for help with monoclonal antibody production. G.H., F.R., and C.F.B. are employees of Isis Pharmaceutical Corp., and M.A.P. is an employee of Genzyme Corp. They may materially benefit either directly or indirectly through stock options. Y.H., K.S., and A.R.K., along with their employer, Cold Spring Harbor Laboratory, could materially benefit if a therapeutic for SMA results from this work. A.R.K. serves on the scientific advisory board of two nonprofit SMA foundations, and is a consultant for Isis Pharmaceutical Corp.

\section{References}

Allo M, Buggiano V, Fededa JP, Petrillo E, Schor I, de la Mata M, Agirre E, Plass M, Eyras E, Elela SA, et al. 2009. Control of alternative splicing through siRNA-mediated transcriptional gene silencing. Nat Struct Mol Biol 16: 717-724.

Arai H, Tanabe Y, Hachiya Y, Otsuka E, Kumada S, Furushima W, Kohyama J, Yamashita S, Takanashi J, Kohno Y. 2005. Finger cold-induced vasodilatation, sympathetic skin response, and $\mathrm{R}-\mathrm{R}$ interval variation in patients with progressive spinal muscular atrophy. J Child Neurol 20: 871-875.

Araujo Ade Q, Araujo M, Swoboda KJ. 2009. Vascular perfusion abnormalities in infants with spinal muscular atrophy. J Pediatr 155: 292-294.

Baker BF, Lot SS, Condon TP, Cheng-Flournoy S, Lesnik EA, Sasmor HM, Bennett CF. 1997. 2'-O-(2-methoxy)ethyl-modified anti-intercellular adhesion molecule 1 (ICAM-1) oligonucleotides selectively increase the ICAM-1 mRNA level and inhibit formation of the ICAM-1 translation initiation complex in human umbilical vein endothelial cells. I Biol Chem 272: 11994-12000. 
Baughan TD, Dickson A, Osman EY, Lorson CL. 2009. Delivery of bifunctional RNAs that target an intronic repressor and increase SMN levels in an animal model of spinal muscular atrophy. Hum Mol Genet 18: 1600-1611.

Belverud S, Mogilner A, Schulder M. 2008. Intrathecal pumps. Neurotherapeutics 5: 114-122.

Butler M, Stecker K, Bennett CF. 1997. Cellular distribution of phosphorothioate oligodeoxynucleotides in normal rodent tissues. Lab Invest 77: 379-388.

Butler M, Crooke RM, Graham MJ, Lemonidis KM, Lougheed M, Murray SF, Witchell D, Steinbrecher U, Bennett CF. 2000. Phosphorothioate oligodeoxynucleotides distribute similarly in class A scavenger receptor knockout and wild-type mice. I Pharmacol Exp Ther 292: 489-496.

Cartegni L, Krainer AR. 2003. Correction of disease-associated exon skipping by synthetic exon-specific activators. Nat Struct Biol 10: 120-125.

Coady TH, Lorson CL. 2010. Trans-splicing-mediated improvement in a severe mouse model of spinal muscular atrophy. I Neurosci 30: 126-130.

Coady TH, Shababi M, Tullis GE, Lorson CL. 2007. Restoration of SMN function: Delivery of a trans-splicing RNA re-directs SMN2 pre-mRNA splicing. Mol Ther 15: 1471-1478.

Coovert DD, Le TT, McAndrew PE, Strasswimmer J, Crawford TO, Mendell JR, Coulson SE, Androphy EJ, Prior TW, Burghes AH. 1997. The survival motor neuron protein in spinal muscular atrophy. Hum Mol Genet 6: 1205-1214.

Crawford TO. 2003. Spinal muscular atrophies. ButterworthHeinemann, Philadelphia.

Crooke ST. 2004. Antisense strategies. Curr Mol Med 4: 465487.

Foust KD, Wang X, McGovern VL, Braun L, Bevan AK, Haidet AM, Le TT, Morales PR, Rich MM, Burghes AH, et al. 2010. Rescue of the spinal muscular atrophy phenotype in a mouse model by early postnatal delivery of SMN. Nat Biotechnol 28: 271-274.

Gabanella F, Butchbach ME, Saieva L, Carissimi C, Burghes AH, Pellizzoni L. 2007. Ribonucleoprotein assembly defects correlate with spinal muscular atrophy severity and preferentially affect a subset of spliceosomal snRNPs. PLOS ONE 2: e921. doi: 10.1371/journal.pone.0000921.

Gavrilina TO, McGovern VL, Workman E, Crawford TO, Gogliotti RG, DiDonato CJ, Monani UR, Morris GE, Burghes AH. 2008. Neuronal SMN expression corrects spinal muscular atrophy in severe SMA mice while muscle-specific SMN expression has no phenotypic effect. Hum Mol Genet 17: 1063-1075.

Geary RS, Yu RZ, Watanabe T, Henry SP, Hardee GE, Chappell A, Matson J, Sasmor H, Cummins L, Levin AA. 2003. Pharmacokinetics of a tumor necrosis factor- $\alpha$ phosphorothioate 2'-O-(2-methoxyethyl) modified antisense oligonucleotide: Comparison across species. Drug Metab Dispos 31: 1419-1428.

Geib T, Hertel KJ. 2009. Restoration of full-length SMN promoted by adenoviral vectors expressing RNA antisense oligonucleotides embedded in U7 snRNAs. PLOS ONE 4: e8204. doi: 10.1371/journal.pone.0008204.

Glass CK, Saijo K, Winner B, Marchetto MC, Gage FH. 2010. Mechanisms underlying inflammation in neurodegeneration. Cell 140: 918-934.

Gogliotti RG, Hammond SM, Lutz C, Didonato CJ. 2010. Molecular and phenotypic reassessment of an infrequently used mouse model for spinal muscular atrophy. Biochem Biophys Res Commun 391: 517-522.

Hsieh-Li HM, Chang JG, Jong YJ, Wu MH, Wang NM, Tsai CH, Li H. 2000. A mouse model for spinal muscular atrophy. Nat Genet 24: 66-70.
Hua Y, Vickers TA, Baker BF, Bennett CF, Krainer AR. 2007. Enhancement of SMN2 exon 7 inclusion by antisense oligonucleotides targeting the exon. PLOS Biol 5: e73. doi: 10.1371/journal.pbio.0050073.

Hua Y, Vickers TA, Okunola HL, Bennett CF, Krainer AR. 2008. Antisense masking of an hnRNP A1/A2 intronic splicing silencer corrects SMN2 splicing in transgenic mice. Am I Hum Genet 82: 834-848.

Kolb SJ, Battle DJ, Dreyfuss G. 2007. Molecular functions of the SMN complex. J Child Neurol 22: 990-994.

Kumar P, Wu H, McBride JL, Jung KE, Kim MH, Davidson BL, Lee SK, Shankar P, Manjunath N. 2007. Transvascular delivery of small interfering RNA to the central nervous system. Nature 448: 39-43.

Le TT, Pham LT, Butchbach ME, Zhang HL, Monani UR, Coovert DD, Gavrilina TO, Xing L, Bassell GJ, Burghes AH. 2005. SMN $\Delta 7$, the major product of the centromeric survival motor neuron (SMN2) gene, extends survival in mice with spinal muscular atrophy and associates with fulllength SMN. Hum Mol Genet 14: 845-857.

Lefebvre S, Burglen L, Reboullet S, Clermont O, Burlet P, Viollet L, Benichou B, Cruaud C, Millasseau P, Zeviani M, et al. 1995. Identification and characterization of a spinal muscular atrophy-determining gene. Cell 80: 155-165.

Lefebvre S, Burlet P, Liu Q, Bertrandy S, Clermont O, Munnich A, Dreyfuss G, Melki J. 1997. Correlation between severity and SMN protein level in spinal muscular atrophy. Nat Genet 16: 265-269.

Lim SR, Hertel KJ. 2001. Modulation of survival motor neuron pre-mRNA splicing by inhibition of alternative $3^{\prime}$ splice site pairing. J Biol Chem 276: 45476-45483.

Lima WF, Wu H, Nichols JG, Sun H, Murray HM, Crooke ST. 2009. Binding and cleavage specificities of human Argonaute2. J Biol Chem 284: 26017-26028.

Liu Q, Dreyfuss G. 1996. A novel nuclear structure containing the survival of motor neurons protein. EMBO J 15: 3555-3565.

Lunn MR, Wang CH. 2008. Spinal muscular atrophy. Lancet 371: 2120-2133.

Madocsai C, Lim SR, Geib T, Lam BJ, Hertel KJ. 2005. Correction of SMN2 pre-mRNA splicing by antisense U7 small nuclear RNAs. Mol Ther 12: 1013-1022.

McWhorter ML, Monani UR, Burghes AH, Beattie CE. 2003. Knockdown of the survival motor neuron (Smn) protein in zebrafish causes defects in motor axon outgrowth and pathfinding. J Cell Biol 162: 919-931.

Meister G, Buhler D, Pillai R, Lottspeich F, Fischer U. 2001. A multiprotein complex mediates the ATP-dependent assembly of spliceosomal U snRNPs. Nat Cell Biol 3: 945-949.

Meyer K, Marquis J, Trub J, Nlend Nlend R, Verp S, Ruepp MD, Imboden H, Barde I, Trono D, Schumperli D. 2009. Rescue of a severe mouse model for spinal muscular atrophy by U7 snRNAmediated splicing modulation. Hum Mol Genet 18: 546-555.

Miyajima H, Miyaso H, Okumura M, Kurisu J, Imaizumi K. 2002. Identification of a cis-acting element for the regulation of SMN exon 7 splicing. I Biol Chem 277: 23271-23277.

Monani UR, Sendtner M, Coovert DD, Parsons DW, Andreassi C, Le TT, Jablonka S, Schrank B, Rossol W, Prior TW, et al. 2000. The human centromeric survival motor neuron gene (SMN2) rescues embryonic lethality in $\mathrm{Smn}^{-1-}$ mice and results in a mouse with spinal muscular atrophy. Hum Mol Genet 9: 333-339.

Munsat TL, Davies KE. 1992. International SMA consortium meeting. (26-28 June 1992, Bonn, Germany). Neuromuscul Disord 2: 423-428.

Narver HL, Kong L, Burnett BG, Choe DW, Bosch-Marce M, Taye AA, Eckhaus MA, Sumner CJ. 2008. Sustained 
Hua et al.

improvement of spinal muscular atrophy mice treated with trichostatin A plus nutrition. Ann Neurol 64: 465470.

Passini MA, Bu J, Roskelley EM, Richards AM, Sardi SP, O'Riordan CR, Klinger KW, Shihabuddin LS, Cheng SH. 2010. CNS-targeted gene therapy improves survival and motor function in a mouse model of spinal muscular atrophy. I Clin Invest 120: 1253-1264.

Pellizzoni L, Yong J, Dreyfuss G. 2002. Essential role for the SMN complex in the specificity of snRNP assembly. Science 298: $1775-1779$.

Riessland M, Ackermann B, Forster A, Jakubik M, Hauke J, Garbes L, Fritzsche I, Mende Y, Blumcke I, Hahnen E, et al. 2010. SAHA ameliorates the SMA phenotype in two mouse models for spinal muscular atrophy. Hum Mol Genet 19: 1492-1506.

Russman BS. 2007. Spinal muscular atrophy: Clinical classification and disease heterogeneity. I Child Neurol 22: 946-951.

Saito T. 2006. In vivo electroporation in the embryonic mouse central nervous system. Nat Protoc 1: 1552-1558.

Schrank B, Gotz R, Gunnersen JM, Ure JM, Toyka KV, Smith AG, Sendtner M. 1997. Inactivation of the survival motor neuron gene, a candidate gene for human spinal muscular atrophy, leads to massive cell death in early mouse embryos. Proc Natl Acad Sci 94: 9920-9925.

Singh NK, Singh NN, Androphy EJ, Singh RN. 2006. Splicing of a critical exon of human survival motor neuron is regulated by a unique silencer element located in the last intron. Mol Cell Biol 26: 1333-1346.

Skordis LA, Dunckley MG, Yue B, Eperon IC, Muntoni F. 2003. Bifunctional antisense oligonucleotides provide a trans-acting splicing enhancer that stimulates SMN2 gene expression in patient fibroblasts. Proc Nat1 Acad Sci 100: 4114-4119.

Smith RA, Miller TM, Yamanaka K, Monia BP, Condon TP, Hung G, Lobsiger CS, Ward CM, McAlonis-Downes M, Wei $\mathrm{H}$, et al. 2006. Antisense oligonucleotide therapy for neurodegenerative disease. J Clin Invest 116: 2290-2296.

Tsai LK, Tsai MS, Lin TB, Hwu WL, Li H. 2006. Establishing a standardized therapeutic testing protocol for spinal muscular atrophy. Neurobiol Dis 24: 286-295.

Tsai LK, Tsai MS, Ting CH, Li H. 2008. Multiple therapeutic effects of valproic acid in spinal muscular atrophy model mice. J Mol Med 86: 1243-1254.

Vinogradov SV, Batrakova EV, Kabanov AV. 2004. Nanogels for oligonucleotide delivery to the brain. Bioconjug Chem 15: 50-60.

Wang $\mathrm{CH}$, Finkel RS, Bertini ES, Schroth $\mathrm{M}$, Simonds A, Wong B, Aloysius A, Morrison L, Main M, Crawford TO, et al. 2007. Consensus statement for standard of care in spinal muscular atrophy. J Child Neurol 22: 1027-1049.

Whitesell L, Geselowitz D, Chavany C, Fahmy B, Walbridge S, Alger JR, Neckers LM. 1993. Stability, clearance, and disposition of intraventricularly administered oligodeoxynucleotides: Implications for therapeutic application within the central nervous system. Proc Natl Acad Sci 90: 4665-4669.

Williams JH, Schray RC, Patterson CA, Ayitey SO, Tallent MK, Lutz GJ. 2009. Oligonucleotide-mediated survival of motor neuron protein expression in CNS improves phenotype in a mouse model of spinal muscular atrophy. I Neurosci 29: 7633-7638.

Yang ZF, Ho DW, Lau CK, Lam CT, Lum CT, Poon RT, Fan ST. 2005. Allograft inflammatory factor-1 (AIF-1) is crucial for the survival and pro-inflammatory activity of macrophages. Int Immunol 17: 1391-1397.

Zhang H, Xing L, Rossoll W, Wichterle H, Singer RH, Bassell GJ. 2006. Multiprotein complexes of the survival of motor neuron protein SMN with Gemins traffic to neuronal processes and growth cones of motor neurons. J Neurosci 26: 8622-8632. 


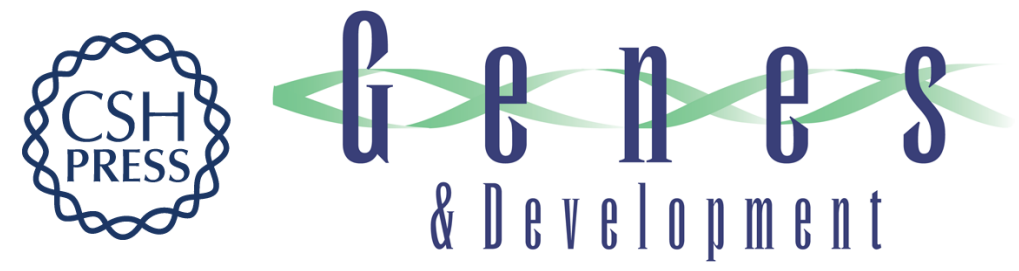

\title{
Antisense correction of SMN2 splicing in the CNS rescues necrosis in a type III SMA mouse model
}

\author{
Yimin Hua, Kentaro Sahashi, Gene Hung, et al.
}

Genes Dev. 2010, 24: originally published online July 12, 2010

Access the most recent version at doi:10.1101/gad.1941310

\section{Supplemental http://genesdev.cshlp.org/content/suppl/2010/07/06/gad.1941310.DC1 Material}

Related Content

References

\section{License}

Email Alerting

Service
This article cites 57 articles, 15 of which can be accessed free at:

http://genesdev.cshlp.org/content/24/15/1634.full.html\#ref-list-1

Articles cited in:

http://genesdev.cshlp.org/content/24/15/1634.full.html\#related-urls

Antisense oligonucleotides and spinal muscular atrophy: skipping along Arthur H.M. Burghes and Vicki L. McGovern

Genes Dev. August , 2010 24: 1574-1579

Receive free email alerts when new articles cite this article - sign up in the box at the top right corner of the article or click here.

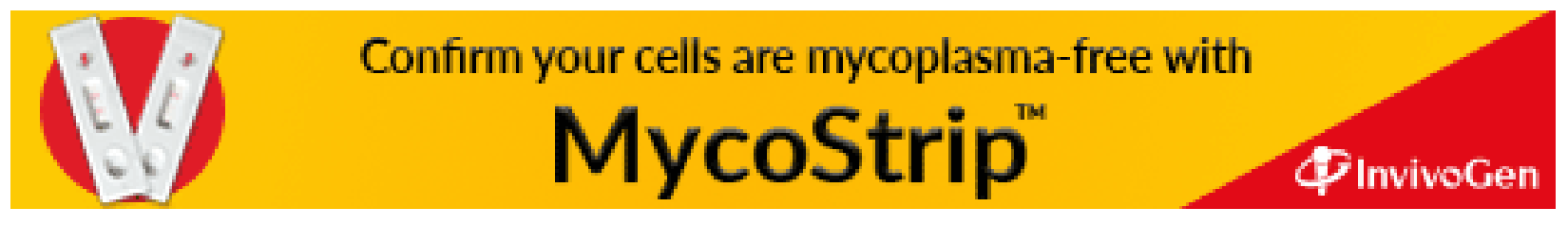

